\title{
Mitigation of High-Temperature Damage by Application of Kaolin and Pinolene on Young Olive Trees (Olea europaea L.): A Preliminary Experiment to Assess Biometric, Eco-Physiological and Nutraceutical Parameters
}

\author{
Aurora Cirillo $^{1}$, Stefano Conti ${ }^{1, *(\mathbb{D})}$, Giulia Graziani ${ }^{2} \mathbb{D}$, Christophe El-Nakhel $^{1, *(\mathbb{D}}$, Youssef Rouphael ${ }^{1}(\mathbb{D}$, \\ Alberto Ritieni ${ }^{2,3}$ and Claudio Di Vaio ${ }^{1}$ (D) \\ 1 Department of Agricultural Sciences, University of Naples Federico II, Via Università 100, 80055 Portici, Italy; \\ aurora.cirillo@unina.it (A.C.); youssef.rouphael@unina.it (Y.R.); claudio.divaio@unina.it (C.D.V.) \\ 2 Department of Pharmacy, University of Naples Federico II, Via Domenico Montesano 49, 80131 Naples, Italy; \\ giulia.graziani@unina.it (G.G.); alberto.ritieni@unina.it (A.R.) \\ 3 Unesco Health Education and Sustainable Development, 80131 Naples, Italy \\ * Correspondence: stefano.conti@unina.it (S.C.); christophe.elnakhel@unina.it (C.E.-N.)
}

check for updates

Citation: Cirillo, A.; Conti, S.; Graziani, G.; El-Nakhel, C.; Rouphael, Y.; Ritieni, A.; Di Vaio, C. Mitigation of High-Temperature Damage by Application of Kaolin and Pinolene on Young Olive Trees (Olea europaea L.): A Preliminary Experiment to Assess Biometric, Eco-Physiological and Nutraceutical Parameters. Agronomy 2021, 11, 1884. https://doi.org/10.3390/ agronomy11091884

Academic Editor: Jane K. Dever

Received: 2 September 2021

Accepted: 16 September 2021

Published: 20 September 2021

Publisher's Note: MDPI stays neutral with regard to jurisdictional claims in published maps and institutional affiliations.

Copyright: (c) 2021 by the authors. Licensee MDPI, Basel, Switzerland. This article is an open access article distributed under the terms and conditions of the Creative Commons Attribution (CC BY) license (https:/ / creativecommons.org/licenses/by/ $4.0 /)$.

\begin{abstract}
Various products are used to mitigate the negative effects of abiotic stress in olive trees. The aim of the research was to examine an anti-transpirant product (Vapor Gard ${ }^{\circledR}, \mathrm{V}$ ) and a kaolinbased product (Manisol, K) effect on the growth of two-year-old olive tree seedlings under high temperature. The study was conducted in a greenhouse on trees of a native cultivar of Campania (cv. Salella) grown in pot during the growing season from May to September 2020. The experimental design included two products: di-1-p-menthene (product V) and kaolin (product K), applied five times at 20 day intervals compared with a control. The following biometric, physiological, and nutraceutical parameters were evaluated: stomatal conductance, chlorophyll $a$ fluorescence, Soil Plant Analysis Development (SPAD) index, relative water content (RWC), shoots growth, total leaf area per plant, trunk cross-sectional area, dry matter partitioning, total polyphenols, and antioxidant activity. The results obtained showed that the application of di-1-p-menthene $(\mathrm{V})$ was able to induce a significant improvement of shoots growth $(+37.22 \%)$ and trunk cross-sectional area $(+46.60 \%)$ and a reduction of the stomatal conductance and an increase of leaf RWC values. Application with kaolin had positive effects on the total polyphenol content, with an increase over the control of $240.33 \%$ and higher antioxidant activity values. Further studies are necessary to determine the effect of these products on the biometric, physiological and nutraceutical parameters of mature olive trees cultivated in open field conditions.
\end{abstract}

Keywords: anti-transpirant; stomatal conductance; chlorophyll $a$ fluorescence; RWC; total polyphenols; antioxidant activity

\section{Introduction}

The olive tree (Olea europaea L.) is one of the most important crops in the Mediterranean basin, and its growth and development are mainly controlled by atmospheric conditions [1,2]. In recent years, with the scenario of climate change, this cultivar is strongly exposed to thermal and hydric stresses during the growing season, mostly during summer and in the innermost areas of Europe [3]. These changes in temperature and precipitation along with a greater frequency of extreme weather have reduced agricultural yield [4,5]. Temperature affects most plant physiological processes, including photosynthesis and transpiration, which are both regulated by stomatal conductance and which mutually affect each other [6]. The atmospheric $\mathrm{CO}_{2}$ concentration is increasing, and in addition to its direct effects on plant growth, this change is expected to raise the global mean surface temperature and result in an increase in the severity of summer drought [7]. The olive tree 
is considered to be a sclerophyllous, high-temperature, and drought-tolerant species with a photosynthetic apparatus resistant enough to moderate water stress, while the stomata are the main limiting factors to carbon assimilation [8]. In conditions of low available water and high temperatures, the olive tree undergoes significant stress, resulting in reduced productivity [9-11]; one of the immediate responses is the reduction of stomata openings in order to decrease the transpiration rate and maintain positive turgor pressure of the cells [12-14]. In olive trees, the recovery after stress is a complex process; the trees restore the water status rapidly along with a slow recovery of stomatal conductance [15]. A conservative bearing after re-watering has been identified, as trees rapidly restore the water status along with a slow recovery of stomatal conductance [16].

Although olive trees adapt well to stressful conditions, high expenditure of energy is required by the plant to withstand stressful conditions [10]. Water deficit, commonly associated to heat and high irradiance stresses, impairs plant water status, drives stomatal closure, mesophyll compactness, and photoinhibition, compromising photosynthetic capacity $[11,17,18]$. Photosynthesis is the primary factor of plant growth [19], and all stress factors affecting the efficiency of photosynthesis lead to reduced plant biomass and growth [20]. The measurement of Chlorophyll $a(\mathrm{Chl} a)$ fluorescence [21,22] is an important tool for studying the photosynthetic metabolism.

It is important to adopt agronomic practices that allow a better adaptability for drought and high temperature, and therefore the capacity to integrate both tolerance and recovery capacity [15] of olive orchards. One neglected agronomic technique that has the potential to significantly contribute to abiotic stress amelioration in food crop production is the use of anti-transpirants. These latter are substances that are applied on leaves to reduce transpiration, and hence improve plant water potential [23]. Originally, kaolin was developed for the suppression of pests in many crops [24], but later, it has been demonstrated that the white kaolin film formed on the leaf surface increases the reflection of incoming solar radiation. Kaolin has a reflective power and redistributes the radiation throughout the plant, reaching both leaf surfaces and shaded plant canopy areas [25,26]. According to the above, kaolin also has an anti-transpirant effect: reducing heat stress and solar injury to the entire tree canopy, leaf, and fruit and, in particular, their temperature [25]. However, products based on 1-p-menthene (pinolene), which is an emulsifiable terpenic polymer distilled from conifer resins, create a thin, similar to a physical barrier, transparent and flexible coat that stops water dispersion [27], decreases the stomatal conductance, and consequently reduces transpirational losses, wilting, and leaf abscission, and favors improving plant water status [28].

In an agronomic scenario in which the damage from high temperatures caused by climate change is increasingly widespread, the aim of our preliminary study was to evaluate the effects of two anti-transpirants products on the improvement of growth and physiological status of young olive trees, grown in greenhouses under high temperatures, and the effects on bioactive components in their leaves.

\section{Materials and Methods}

\subsection{Growth Conditions, Experimental Design and Products Applications}

The trial was conducted in a greenhouse at the University of Naples "Federico II"Department of Agriculture, situated in Portici (Province of Naples, Italy; $40^{\circ} 48^{\prime} \mathrm{N}, 14^{\circ} 20^{\prime} \mathrm{E}$, m.s.l) between the end of May and the end of September 2020, adopting 2-year-old potted olive trees cv. Salella. Temperatures were recorded continuously using Tinytag data loggers (Gemini data loggers, Chichester, UK) placed at canopy level of the trees. At the beginning of the trial, all plants were characterized by homogeneous growing characteristics; and $0.05 \mathrm{~kg}$ /tree of Nitrophoska Gold (Compo Expert, Cesano Maderno, MB, Italy) was added to the substrate.

The study included two spray treatments, conducted five times during the growing season: 25 May, 15 June, 06 July, 27 July and 24 August, compared with a control thesis:

(1) Control (C) plants treated only with water; 
(2) Kaolin (K), the product used was Manisol (Kaolin + Copper 5\%) from Manica S.p.a (Rovereto, Italy), which was applied by foliar application with $80 \mathrm{~g}$ in $2 \mathrm{~L}$ of water;

(3) Di-1-p-menthene $\left(\mathrm{C}_{20} \mathrm{H}_{34}\right)(\mathrm{V})$, a terpenic polymer also known as pinolene, in the form of a water emulsifiable organic concentrate. The product used was Vapor Gard ${ }^{\circledR}$ from Biogard ${ }^{\circledR}$ (Bergamo, Italy), which was applied by foliar application with $20 \mathrm{ml}$ in $2 \mathrm{~L}$ of water.

The two treatments were sprayed using a portable pump. Plants were irrigated with water equal to $100 \%$ of the evapotranspiration (ET), calculated by weight. A drip irrigation was considered by placing two drippers $(2 \mathrm{~L} / \mathrm{h})$ per plant. The system was fed by electric pumps, and irrigation was automatized due to a timer. For each treatment, ten technical replicates were utilized, each consisting of a single tree.

\subsection{Biometric and Physiological Analysis}

During the growing season, the following measurements were performed: (i) shoots growth with a digital caliber (Borletti CDJB20 accuracy $0.03 \mathrm{~mm}$, Antegnate (BG), Italy), (ii) the circumference of the trunk at $3 \mathrm{~cm}$ above the soil, in order to determine the increase in the trunk cross-sectional area (TCSA) calculated by standard formula (girth ${ }^{2} / 4 \pi$ ), and (iii) leaf number per plant to determine leaf area per plant using imageJ software version 1.50 (Wayne Rasband, National Institute of Health, Bethesda, MD, USA).

On fully developed leaves, the stomatal conductance was measured using a Porometer (Li-1600 Steady State Porometer, Lincoln, NE, USA) taking 6 measurements per treatments; leaf soil plant development (SPAD) index was assessed by taking 20 measurements per treatments using a chlorophyll meter SPAD-502 (Konica-Minolta, Osaka, Japan). Plant water status was assessed by calculating the leaf relative water content (RWC) as follows. Immediately after sampling, leaves were placed in plastic bags inside a cooler box and transferred to the laboratory where the fresh weight (fw) was recorded. Due to the thick cuticle/epidermal layers, the sampled leaves were then rehydrated for $48 \mathrm{~h}$ in distilled water at $4{ }^{\circ} \mathrm{C}$ in the dark prior to measuring the rehydrated weight (rw). Subsequently, the same leaves were dehydrated for at least 48 hours at $80{ }^{\circ} \mathrm{C}$ until constant weight was reached, before their dry weight ( $\mathrm{dw}$ ) was measured. RWC (\%) was calculated as:

$$
\operatorname{RWC}(\%)=([\mathrm{fw}-\mathrm{dw}] /[\mathrm{rw}-\mathrm{dw}]) * 100
$$

These eco-physiological measurements were performed three times during the trial: on 29 June, 21 July, and 25 August.

Before the end of the experiment, chlorophyll $a$ fluorescence measurements were recorded in the field on 30 min dark-adapted leaves using a PAR-FluorPen FP 110/D portable fluorimeter (Photon Systems Instruments, Drásov, Czech Republic) equipped with detachable leaf-clip. Measurements occurred at 9 a.m. and 1:30 p.m., for a one hour lap each, according to the procedure reported by Mola et al. [29]. Fluorescence data were analyzed by the FluorPen software ver. 1.1 (Photon Systems Instruments, Drásov, Czech Republic), and the $\mathrm{F}_{\mathrm{v}} / \mathrm{F}_{\mathrm{m}}$ parameter was calculated as follows:

$$
\mathrm{F}_{\mathrm{v}} / \mathrm{F}_{\mathrm{m}}=\left(\mathrm{F}_{\mathrm{m}}-\mathrm{F}_{0}\right) / \mathrm{F}_{\mathrm{m}}
$$

where $F_{0}$ is the basal fluorescence recorded at $40 \mu$ s and $F_{m}$ is the peak of the fast fluorescence rise following illumination of the dark-adapted leaves with a saturating flash of light.

At the end of the growing season, the plants were harvested to determine the dry matter partitioning of the various components of the trees (roots, leaves, wood and total). Then, the root/canopy ratio of the individual plants was calculated. At the end of the season, six samples of leaves per treatment were frozen and freeze-dried to determine the polyphenol content and antioxidant activity. 


\subsection{Determination of Leaf Polyphenols}

\subsubsection{Chemicals}

All the standards for the analyses were the same used in a previous study conducted by Di Vaio et al. [30] on a minor autochthonous cultivar of olive of the Campania Region.

\subsubsection{Ultrasound-Assisted Extraction of Polyphenolic Compounds}

Lyophilized samples were extracted using the method reported in the literature [31] with few modifications. In particular, $0.3 \mathrm{~g}$ of dried sample was extracted with $15 \mathrm{~mL}$ of methanol/water $(80: 20 \mathrm{v} / \mathrm{v}, 0.1 \%$ formic acid) by sonication at room temperature for $15 \mathrm{~min}$. Samples were centrifuged to $4000 \mathrm{rpm}$ at $4{ }^{\circ} \mathrm{C}$ for $10 \mathrm{~min}$, and the pellets were extracted again in the same way. The supernatants were collected, filtered through $0.45 \mathrm{~mm}$ nylon syringe membranes, and then used for high-resolution mass spectrometry analysis and antioxidant activity assay.

\subsubsection{UHPLC-HRMS Analysis of Polyphenolic Compounds}

An Ultra-High-Pressure Liquid Chromatograph (UHPLC, Dionex UltiMate 3000, Thermo Fisher Scientific, Waltham, MA, USA) coupled with a Q-Exactive Orbitrap mass spectrometer (UHPLC, Thermo Fischer Scientific, MA, USA) was used to investigate the quali-quantitative profile of polyphenolic compounds, by applying the conditions reported in our previous work [32]. All results are expressed as $\mu \mathrm{g} / \mathrm{g} \mathrm{dw}$ of olive leaves.

\subsection{Antioxidant Activity: ABTS Assay}

Determination of the ABTS free radical scavenging activity was conducted following the method described by Re et al. [33].

\subsection{Antioxidant Activity: DPPH Assay}

The DPPH assay was conducted according to the procedure reported by BrandWilliams et al. (1995) [34] with minor modifications. Briefly, methanolic DPPH radical working solution was prepared diluting methanolic DPPH $(4 \mathrm{mg}$ in $10 \mathrm{~mL})$ with methanol until an absorbance value of $0.900 \pm 0.020$ at $517 \mathrm{~nm}$. For the assay, $200 \mu \mathrm{L}$ of sample were added to $1 \mathrm{~mL}$ of radical working solution, and the absorbance value was monitored after $10 \mathrm{~min}$. The results were expressed as Trolox equivalents antioxidant capacity (TEAC, mmol Trolox equivalent $\mathrm{kg}^{-1}$ of dry weight of sample). All determinations were performed in triplicate.

\subsection{Statistical Analysis}

Analysis of variance (two-way ANOVA) was applied to analyze the group means. Duncan's multiple range test was (DMRT) performed for mean separation of each of the significant $(p<0.05)$ measured variables. A principal component analysis (PCA) was executed on biometric, physiological and nutraceutical parameters at the end of growing season, to detect the interrelationship. The statistical package XLSTAT Version 2013 (New York, NY, USA) was implemented for all the analyses.

\section{Results and Discussion}

\subsection{Implications of Kaolin and Pinolene for Biometric and Physiological Parameters}

Mean, maximum and minimum air temperature inside the greenhouse during the cultivation cycle are presented in Figure 1 . The maximum temperatures of $51.74{ }^{\circ} \mathrm{C}$ in July and $49.90^{\circ} \mathrm{C}$ in August were recorded, while the minimum temperature was $23.42{ }^{\circ} \mathrm{C}$ in June (Figure 1).

Figure 2 shows the effect of Kaolin (K) and di-1-p-menthene (V) products on shoots growth of olive plants compared with control (C) during the growing season. No significant difference was shown between the various treatments; on the contrary, a significant difference was highlighted during the days of growing season for the shoots growth. The interaction between treatments and days of measurements $(T \times D)$ was found to be signifi- 
cant with $p<0.001$. At the end of the growing season, $\mathrm{V}$ applications improved the growth of the shoots compared to $\mathrm{C}$ by about $+46.60 \%$. On the contrary, K application did not significantly improve the performance of this parameter with respect to the $C(+10.70 \%)$.

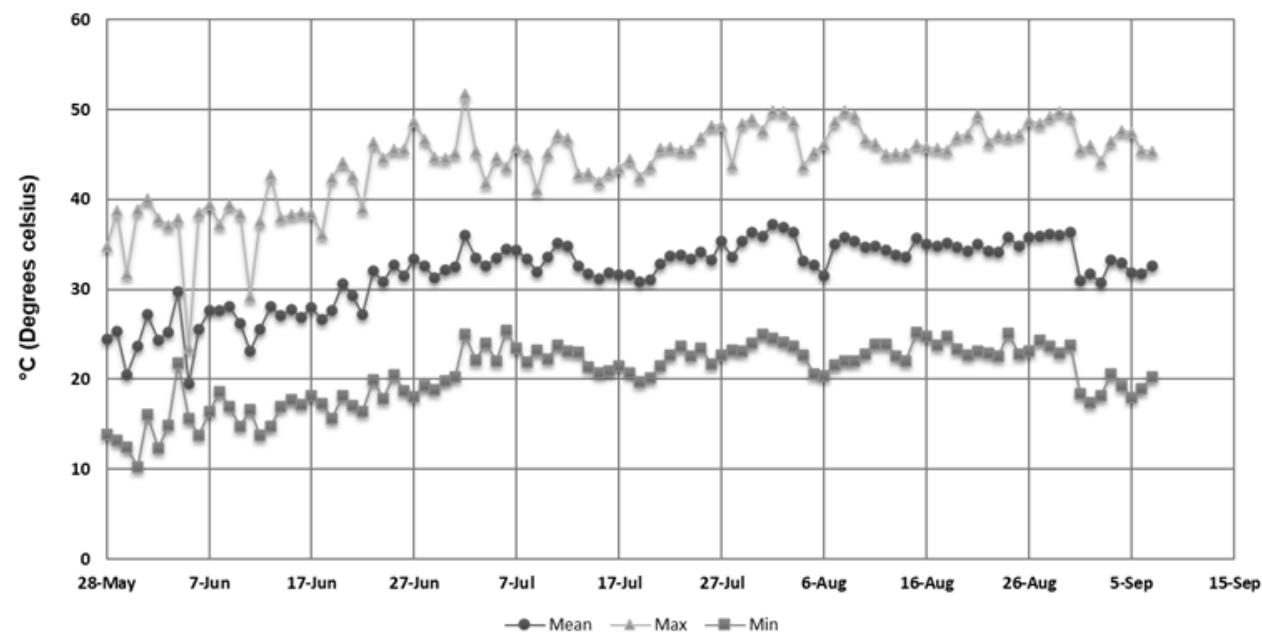

Figure 1. Monthly temperature trend: maximum, minimum, and mean temperature $\left({ }^{\circ} \mathrm{C}\right)$ recorded during the growing season under the greenhouse.

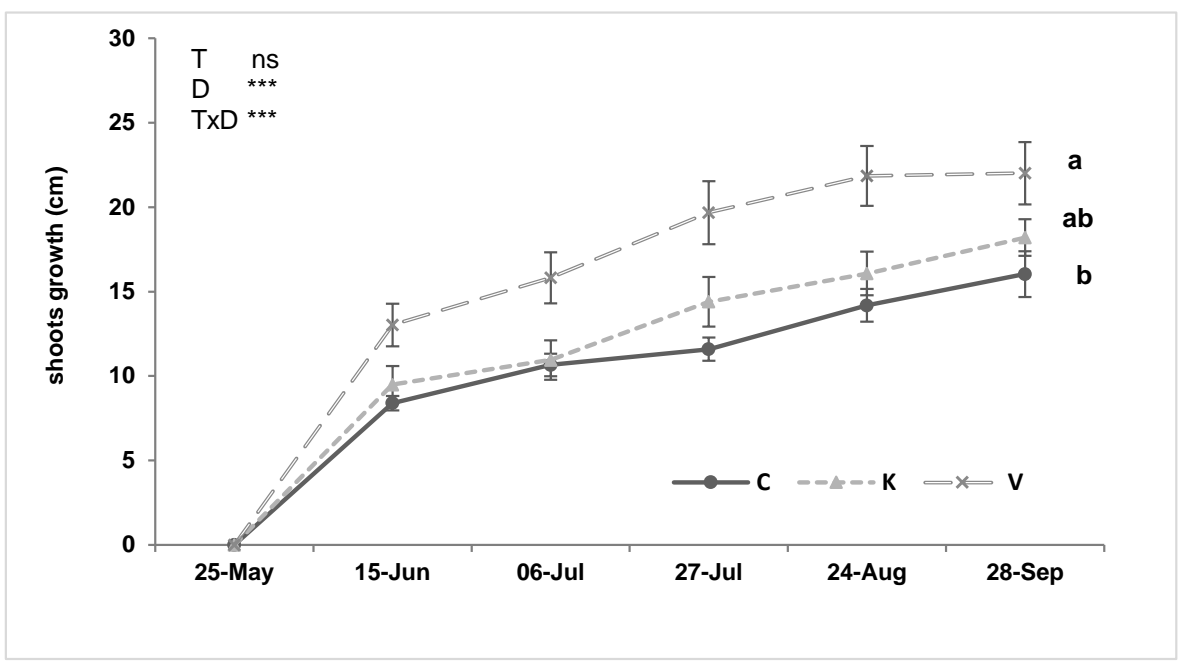

Figure 2. Effects of kaolin (K), di-1-p-menthene (V) on shoots growth during the growing season. $\mathrm{C}$ : control. Different letters indicate significant differences according to Duncan's multiple-range test $(p=0.05)$. Vertical bars indicate \pm SE of the means, $\mathrm{n}=10$ plants for treatments. Asterisks indicate significant effect of biostimulant treatment $(\mathrm{T})$, days of measurements $(\mathrm{D})$, and their interaction $(\mathrm{T} \times \mathrm{D})$, according to two-way ANOVA (ns, ${ }^{* * *}$ non-significant or significant at $p \leq 0.001$, respectively).

At the end of the growing season, $\mathrm{V}$ treatment resulted in significantly higher values of TCSA, in comparison with C $(+34.7 \%)$ and $\mathrm{K}$ treatment $(+41.7)$ (Table 1$)$, in addition to shoots growth being only significantly higher under $\mathrm{V}$ treatment, $37.2 \%$ compared to $C$. Meanwhile, leaf area per plant showed significant differences when plants were treated with $\mathrm{K}$ and $\mathrm{V}$ with respect to $\mathrm{C}$, registering an increase of about $+10.2 \%$ and $+9.4 \%$ respectively. Our results are consistent with those reported previously by Roussos et al. (2010) [35], where plant height in olive trees with kaolin applications did not report significant differences with respect to control. Similar results to ours were also reported by MI et al. [36], where in a test on Ficus carica L., the use of two anti-transpirant types, namely "Folicote" and Vapor-gard, increased growth parameters, yield and fruit quality in the first season. The anti-transpirants products are expected to reduce photosynthesis and hence the growth of the plants. However, since the anti-transpirants close the stomata, the 
plant water potential increases, and it is possible to induce an increase in growth, despite reduced photosynthesis [37].

Table 1. Effect of kaolin (K) and di-1-p-menthene (V) on shoots growth, trunk cross sectional area (TCSA) and leaf area per plant at the end of growing season. C: control.

\begin{tabular}{|c|c|c|c|}
\hline Treatments & Shoots Growth (cm) & $\operatorname{TCSA}\left(\mathrm{cm}^{2}\right)$ & Leaf Area per Plant $\left(\mathrm{cm}^{2}\right)$ \\
\hline C & $14.44 \pm 1.55 \mathrm{~b}$ & $17.05 \pm 1.78 \mathrm{~b}$ & $682.02 \pm 16.00 \mathrm{~b}$ \\
\hline K & $18.20 \pm 1.08 \mathrm{ab}$ & $16.21 \pm 1.51 \mathrm{~b}$ & $759.03 \pm 25.94 \mathrm{a}$ \\
\hline V & $21.17 \pm 1.84 \mathrm{a}$ & $22.97 \pm 2.09 \mathrm{a}$ & $746.30 \pm 23.88 a$ \\
\hline Significance & $* * *$ & * & * \\
\hline
\end{tabular}

Different letters indicate significant differences according to Duncan's multiple-range test $(p=0.05)$. Means $\pm \mathrm{SE}$ (standard error). Significance levels of parameters in ANOVA test: ${ }^{*} p<0.05 ;{ }^{* * *} p<0.001$.

The effect of kaolin (K) and 1-p-menthene (V) applications on eco-physiological parameters are reported in Table 3, after one (29-Jun), two (21-Jul) and three (25 Aug) months of the first application (25 May). Figure 3a shows the stomatal conductance values, where already after one month from the first application, the effects of the treatments were evident.

(a)

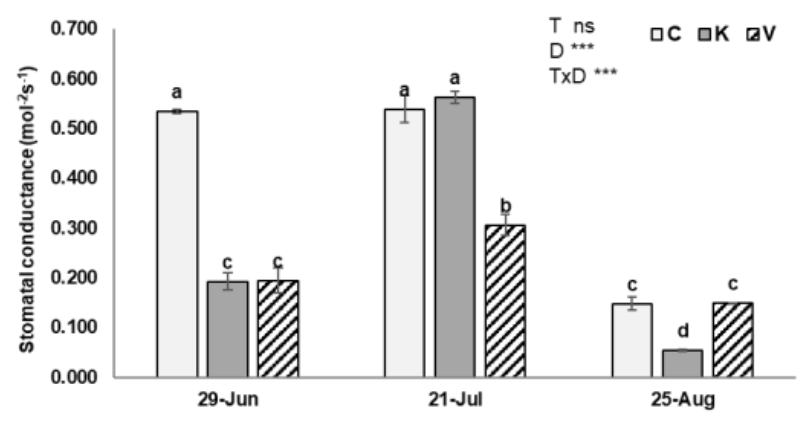

(c)

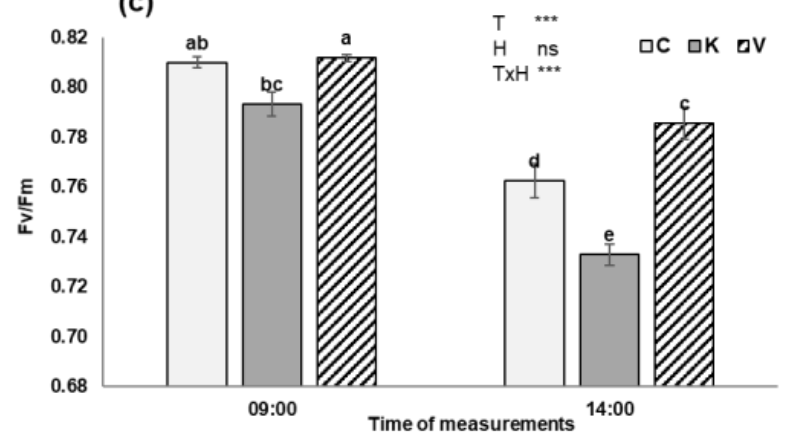

(b)

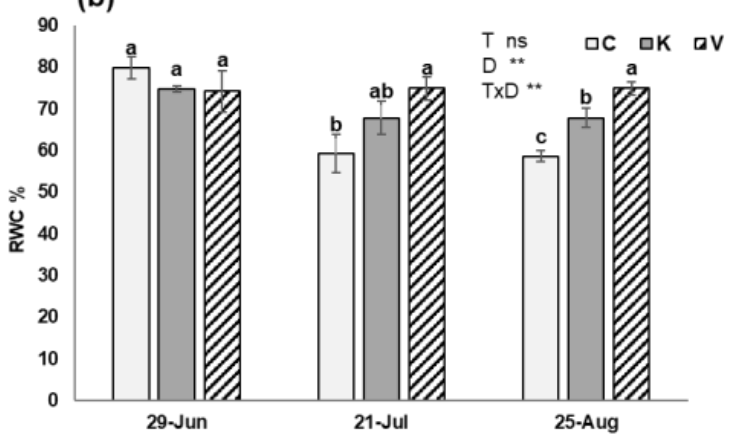

(d)

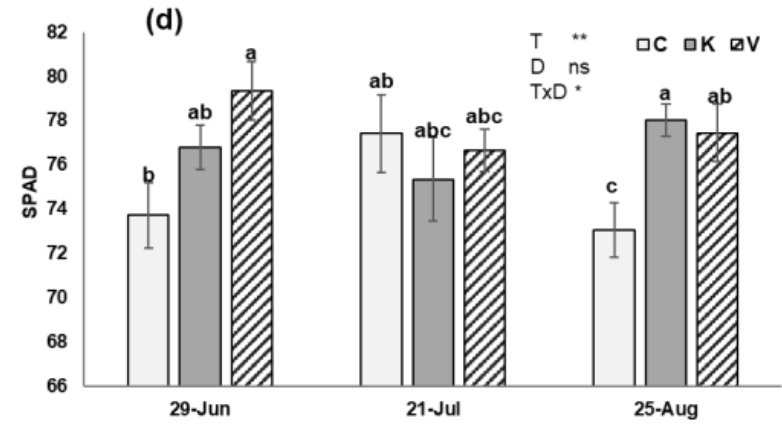

Figure 3. Effect of kaolin (K) and 1-p-menthene (V) after one (29-Jun), two (21-Jul) and three (25 Aug) months by the first application on: stomatal conductance (a), RWC (relative water content) (b), fluorescence $\left(\mathrm{F}_{\mathrm{v}} / \mathrm{F}_{\mathrm{m}}\right)$ measured at different temperature condition at 9:00 $\mathrm{h}$ and at 14:00 h (c). SPAD (soil plant development) index (d), versus C: control. Vertical bars indicate \pm SE (standard error) of the means. Different letters indicate significant differences according to Duncan's multiple-range test $(p=0.05)$. Asterisks indicate significant effect of biostimulant treatment $(\mathrm{T})$, days of measurements (D) and their interaction $(\mathrm{T} \times \mathrm{D})$ according to two-way ANOVA (ns not-significant; ${ }^{*} p<0.05 ;{ }^{* *} p<0.01$; ${ }^{* * *} p<0.001$ ).

No significant difference was shown between the various treatments; on the contrary, a significant difference was highlighted during the days of growing season for the stomatal conductance. The interaction between treatments and days of measurements $(\mathrm{T} \times \mathrm{D})$ was found to be significant with $p<0.001$; conductance values with $C$ applications were equal to $0.53 \mathrm{~mol}^{-2} \mathrm{~s}^{-1}$, significantly higher than the treated plants. During the vegetative season in July, K applications showed an increase in stomatal conductance $\left(0.56 \mathrm{~mol}^{-2} \mathrm{~s}^{-1}\right)$, but at 
the end of the vegetative season, all three treatments showed low conductance values, in particular $\mathrm{K}$, which was statistically different from $\mathrm{C}$ with a reduction of $3.70 \%$. Similar results have also been observed by Di Vaio et al. [38,39] on "Aglianico" and "Falanghina" (Vitis Vinifera L.), where a product based on 1-p-menthene significantly reduced the stomatal conductance and assimilation rate. Stomatal conductance usually decreases at high temperatures; however, this result is probably due to leaf water deficit or large leaf-to-air water vapor concentration differences generated by high temperature $[40,41]$.

Another parameter used for evaluating the state of plants was the relative water content index (RWC) (Figure 3b); in this case, no significant difference was shown between the various treatments, but a significant difference was highlighted during the days of growing season. The interaction between treatments and days of measurements $(T \times D)$ was found to be significant with $p<0.01$. In particular, in June, no statistically significant differences were recorded, as the plants had not yet undergone prolonged thermal stress; in July, only treatment with V reported significant different values, about $+26.39 \%$ higher than C. In August, the effect of stomatal closure of the two spray products was clearly highlighted, as they showed significantly higher values of RWC, about $+15.8 \%$ in $\mathrm{K}$ and $+27.87 \%$ in $\mathrm{V}$ compared to $\mathrm{C}$. Anti-transpirants are chemical compounds used to limit the transpiration process and to maintain the advantageous parameters of the water balance of plants [42], and they are commonly used to reduce leaf water loss. For instance, anti-transpirant products increased the relative water content of Morus alba leaves at different irrigation levels [43]. They may allow a reduction in water transpiration without greatly affecting photosynthetic activity [44]. In addition to the beneficial effect of elevated $\mathrm{CO}_{2}$ concentration on drought stress, anti-transpirants can significantly improve drought tolerance [45]. Our results are in agreement with Mikiciuk et al. [46], where the antitranspirant-used product increased the RWC in leaves of the tested strawberry cultivar by 4.4\%. According to Abdel-Fattah [47], anti-transpirants, which form a film on the surface of the plants, increase the RWC in leaves.

Plants treated with both products had an $\mathrm{F}_{\mathrm{v}} / \mathrm{F}_{\mathrm{m}}$ of 0.81 at 09:00 a.m., corresponding to the optimum value for healthy, non-stressed plants [48], while plants treated with $\mathrm{K}$ showed an $\mathrm{F}_{\mathrm{v}} / \mathrm{F}_{\mathrm{m}}$ of 0.79 always at 09:00 a.m. (Figure 3c).

Significant differences were shown between the various treatments and during the time of measurements. The interaction between temperature and time of measurements $(\mathrm{T} \times \mathrm{H})$ was found to be significant with $p<0.001$. The $\mathrm{F}_{\mathrm{V}} / \mathrm{F}_{\mathrm{m}}$ decreased gradually and at the mid-day measurement; it was significantly lower than that registered at 09:00 a.m. thus evidencing the daily fluctuation in the maximum quantum yield of PSII photochemistry. At 02:00 p.m., significant differences emerged between $C\left(F_{v} / F_{m}=0.76\right), K\left(F_{v} / F_{m}=0.73\right)$ and $\mathrm{V}\left(\mathrm{F}_{\mathrm{V}} / \mathrm{F}_{\mathrm{m}}=0.79\right)$ plants. The $\mathrm{V}$ treatment reduced the mid-day depression in photosynthetic efficiency by narrowing the daily fluctuation in $F_{v} / F_{m}$, while the $K$ treatment increased this depression. Overall, this positive effect of $\mathrm{V}$ application on the plant photosynthetic metabolism may explain the higher growth parameters recorded for plants treated with this anti-transpirant. Our $\mathrm{F}_{\mathrm{v}} / \mathrm{F}_{\mathrm{m}}$ results with $\mathrm{K}$ applications are in contrast with SeguraMonroy et al. [49] findings. The authors noted significant differences in $F_{V} / F_{m}$ ratio due to kaolin treatments in Physalis peruviana L., with untreated plants having reduced quantum efficiency (with kaolin (0.83) vs. without kaolin (0.79)). Our results are consistent with those reported previously by Latocha et al. [50], where anti-transpirant product application increased the chlorophyll content in leaves at the beginning of the experiments, and it enhanced the efficiency of the photosynthetic apparatus during almost the whole experimental period on Actinidia arguta.

Data on the degradation of the leaf chlorophyll molecule after thermal stress conditions were recorded using a Minolta chlorophyll meter SPAD during the vegetative season, showing a significant difference between the various treatments. The interaction between treatments and days of measurements $(T \times D)$ was found to be significant with $p<0.05$. Our results showed, at the end of the test, positive effects of $\mathrm{K}$ and $\mathrm{V}$ products in maintaining higher levels of leaf SPAD than C (Figure 3d). K induced an increase in SPAD index equal 
to $+6.8 \%$ and $\mathrm{V}$ equal to $+6 \%$ compared to $\mathrm{C}$. Higher $\mathrm{F}_{\mathrm{v}} / \mathrm{F}_{\mathrm{m}}$ chlorophyll fluorescence emissions and SPAD index values on anti-transpirant trees compared with $C$, indicating less damage of the photosynthetic apparatus and higher leaf chlorophyll content.

As chlorophyll is the major component of photosynthetic activity [51], it may explain yield increase at harvest in polymer-treated trees due to the improvements in these two measurements. Nevertheless, not all studies are consistent with these findings, since Percival et al. [52] on Aesculus hippocasta-num L. and Quercus robur L showed no significant effects of film-forming polymers on leaf $\mathrm{F}_{\mathrm{v}} / \mathrm{F}_{\mathrm{m}}$ values and SPAD index values compared with $C$.

However, our findings are confirmed by other studies where the SPAD index reading was greater in leaves treated with kaolin [51]; this positive effect on SPAD index was also shown by Lombardini et al. [25] after kaolin treatment.

A possible explanation for the increase of this parameter may be due to the fact that leaves not treated with kaolin can show a lower light reflectance, suggesting an increase of degradation of the photosynthetic pigments [53].

In September, at the end of the test, the plants were sampled to determine the dry matter (Figure 4). An increase in both roots and total dry matter with $\mathrm{V}$ application compared to $\mathrm{C}$ was highlighted, equal to $+17.43 \%$ and $+12.07 \%$, respectively, while $\mathrm{K}$ applications caused a reduction in total dry matter compared to C, equal to $-23.63 \%$. Our findings concerning $\mathrm{K}$ application are consistent with those reported previously by Cantore et al. [24], where the use of kaolin did not affect fruit dry matter. Similar results have also been observed in other previous studies on anti-transpirant products that influenced plant height and total dry matter [42], where the results obtained in greenhouse and field trials on unirrigated sweet corn indicated that significant increases in growth and of dry matter/yield occur in response to Vapor Gard (6\%) treatment. Positive effect of 1-p-menthene-based product on vegetative growth and development may be due to improved plant water status related to lower transpiration [54].

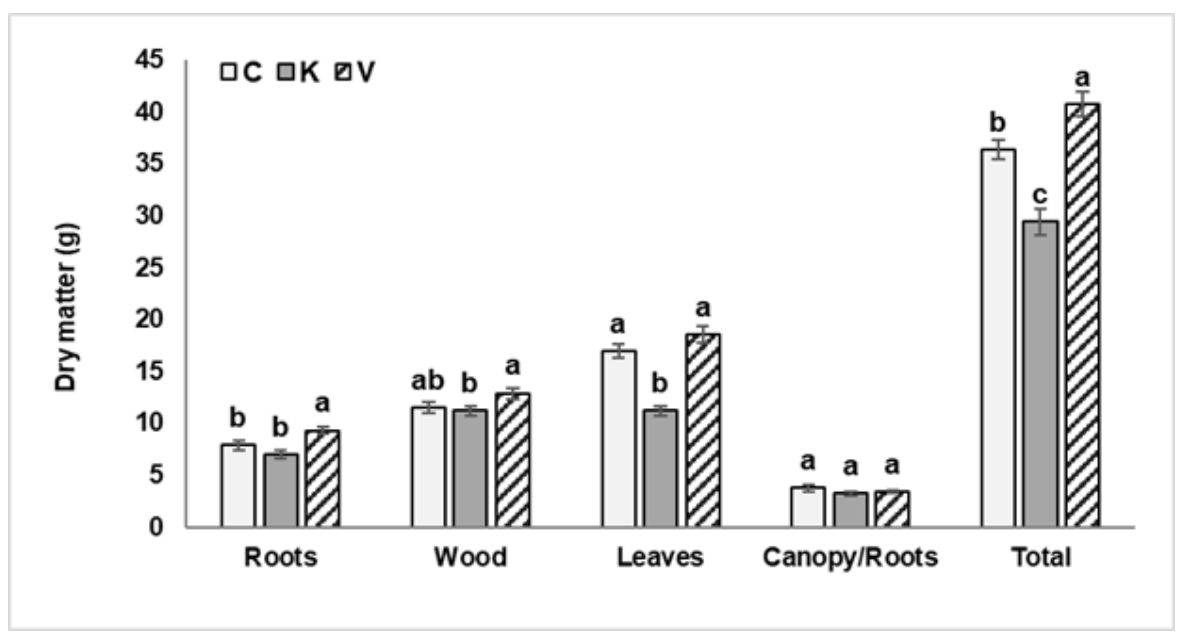

Figure 4. Effect of kaolin (K) and 1-p-menthene (V) on dry matter of roots, wood, leaves, canopy / roots ratio and total dry matter at the end of growing season. C: control. Vertical bars indicate $\pm \mathrm{SE}$ (standard error) of the means. Different letters indicate significant differences according to Duncan's multiple-range test $(p=0.05)$.

\subsection{Analysis of Polyphenols by UHPLC-Q-Orbitrap HRMS}

Table 2 reports the phenolic composition obtained by UHPLC-HRMS analysis and Table 3 shows the quali-quantitative polyphenolic profile of olive leaves in control and treated plants. Single phenolic compounds were identified and quantified using calibration curves built with appropriate reference compounds. As certain standards were not available (the case of secoiridoids), quantification was calculated employing calibration curves of oleuropein, while for the identification, MS/MS experiments had to be used. 
Table 2. Exact mass spectra data (molecular formula, deprotonated molecular ion $\left([\mathrm{M}-\mathrm{H}]^{-}\right)$and accuracy $(\Delta \mathrm{ppm}))$ of olive leaves polyphenols investigated UHPLC-HRMS Orbitrap.

\begin{tabular}{ccccc}
\hline & & Theorical Mass & Experimental Mass & Error \\
\hline Compound & Formula & & {$[\mathrm{M}-\mathrm{H}]^{-}$} & $\Delta \mathrm{ppm}$ \\
\hline Ligstroside & $\mathrm{C} 25 \mathrm{H} 32 \mathrm{O} 12$ & 523.18210 & 523.18079 & -2.50 \\
Oleuropein aglycone & $\mathrm{C} 19 \mathrm{H} 22 \mathrm{O} 8$ & 377.12419 & 377.12442 & 0.61 \\
Verbascoside & $\mathrm{C} 29 \mathrm{H} 36 \mathrm{O} 15$ & 623.19814 & 623.19952 & 2.21 \\
Oleuropein & $\mathrm{C} 25 \mathrm{H} 32 \mathrm{O} 13$ & 539.17701 & 539.17792 & 1.69 \\
OH-tyrosol-glucoside & $\mathrm{C} 13 \mathrm{H} 18 \mathrm{O} 8$ & 301.09289 & 301.09329 & -1.85 \\
Luteolin & $\mathrm{C} 15 \mathrm{H} 10 \mathrm{O} 6$ & 285.04062 & 285.04083 & 0.74 \\
\hline
\end{tabular}

Table 3. Effect of kaolin (K) and 1-p-menthene (V) on phenolic compounds content in leaves of olive trees at the end of growing season. $\mathrm{C}$ : control. $\mathrm{OH}$ : hydroxy.

\begin{tabular}{ccccc}
\hline Polyphenols & \multicolumn{2}{c}{ Treatments } & \multicolumn{2}{c}{ Significance } \\
\hline & $\mathrm{C}$ & $\mathrm{K}$ & $\mathrm{V}$ & $\mathrm{T}$ \\
\hline Ligstroside & $54.01 \pm 1.12 \mathrm{~b}$ & $266.16 \pm 1.54 \mathrm{a}$ & $67.79 \pm 1.54 \mathrm{~b}$ & $* * *$ \\
Oleuropein aglycone & $54.67 \pm 2.02 \mathrm{~b}$ & $230.89 \pm 0.45 \mathrm{a}$ & $45.90 \pm 1.23 \mathrm{c}$ & $* * *$ \\
Verbascoside & $156.91 \pm 4.91 \mathrm{~b}$ & $381.39 \pm 5.71 \mathrm{a}$ & $31.51 \pm 0.34 \mathrm{c}$ & $* * *$ \\
Oleuropein & $629.34 \pm 5.81 \mathrm{~b}$ & $1868.74 \pm 6.54 \mathrm{a}$ & $575.93 \pm 3.58 \mathrm{~b}$ & $* * *$ \\
OH-tyrosol glucoside & $2185.11 \pm 0.34 \mathrm{~b}$ & $8215.27 \pm 8.43 \mathrm{a}$ & $980.91 \pm 7.34 \mathrm{c}$ & $* * *$ \\
Luteolin & $205.00 \pm 3.43 \mathrm{ab}$ & $217.59 \pm 3.94 \mathrm{a}$ & $191.02 \pm 2.58 \mathrm{~b}$ & $\mathrm{~ns}$ \\
\hline Total polyphenols & $3285.04 \mathrm{~b}$ & $11,180.05 \mathrm{a}$ & $1893.07 \mathrm{c}$ & $* * *$ \\
\hline
\end{tabular}

Different letters indicate significant differences according to Duncan's multiple-range test $(p=0.05)$. Significance level of total polyphenols in leaves in ANOVA test: ns not significant; ${ }^{* * *} p<0.001$. All results are expressed as $\mu \mathrm{g} / \mathrm{g} \mathrm{dw}$ of olive leaves.

The Q Exactive Orbitrap LC-MS/MS analysis allowed the separation and identification of six phenolic compounds, already reported in olive leaves. They were identified by comparison of their molecular formula, the fragments obtained, and the order of elution in the literature [32]. The chromatographic separation and qualitative analysis highlighted a nonsubstantial difference in the phenolic composition between the different samples investigated. The two main phenolic compounds detected were oleuropein and tyrosol glucoside in all three treatments. $\mathrm{K}$ treatments showed significantly higher values of hydroxytyrosol glucoside with an increase of $+276.00 \%$ compared to C. On the contrary, V application caused significantly lower values than that of $C(-55.11 \%)$. This trend is also confirmed for oleuropein, where the highest concentration is shown with $\mathrm{K}$ application, which showed an increase compared to C of $+196.94 \%$; on the contrary, V application did not show significant differences compared to C. K application also positively influenced the total polyphenols content; an increase of $+240.33 \%\left(11,180.05 \mu^{-1} \mathrm{~g}^{-1}\right)$ was recorded with respect to $C\left(3285.04 \mu \mathrm{g} \mathrm{g}^{-1}\right)$, while $\mathrm{V}$ treatment induced the lowest accumulation of polyphenols content $\left(1893.07 \mu \mathrm{g} \mathrm{g}^{-1}\right.$. Treatment with pinolene caused an inhibitory effect on PAL activity, thus reducing the concentration of polyphenolic compounds. In literature, a similar effect was associated with the foliar application of the antioxidant 5-hydroxybenzi midazole on "Koroneiki" olive trees [55].

\subsection{Antioxidant Activity of Polyphenolics Extracts}

The results of the antioxidant activity assays, conducted on the polyphenolics extracts of the olive leaves, were reported in Figure 5 and expressed as TEAC (mmol Trolox $\mathrm{kg}^{-1} \mathrm{dw}$ ). According to ABTS test, the values obtained showed an improvement of antioxidant activity with $\mathrm{K}$ treatment $(+49.09 \%)$ and a reduction with $\mathrm{V}$ treatment $(36.16 \%)$ with respect to $\mathrm{C}$. As for the DPPH test, the obtained values showed an improvement of antioxidant activity only with $\mathrm{K}$ treatments, with an increase of $+39.47 \%$ with respect to $\mathrm{C}$. Our results are in agreement with Denaxa et al. [55], who reported that kaolin clay particles resulted in the highest total phenol concentration in young olive plants. In this same study, it was highlighted that Kaolin application resulted in high activities of antioxidant enzymes such as superoxide dismutase, peroxidase and glutathione reductase under water deficit 
compared to other alleviating products in investigation. Brillante et al. [56] reported that pinolene treatment on grapes caused a decrease in sugar content and anthocyanin level compared to control. In addition, recent studies on Vitis Vinifera showed that treatments with kaolin have highlighted positive effects on reducing canopy temperatures, enhancing the accumulation of anthocyanins [57].

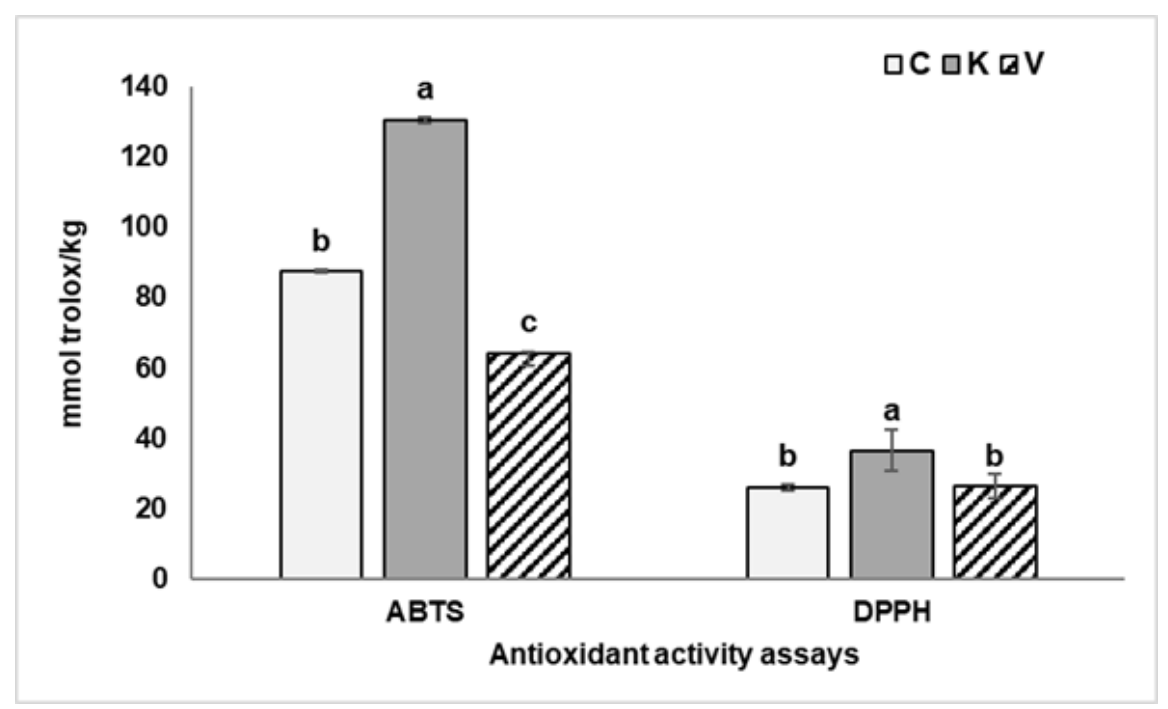

Figure 5. Effect of kaolin (K) and 1-p-menthene (V) on antioxidant activity (ABTS and DPPH) in leaves olive trees at the end of growing season. C: control. Vertical bars indicate $\pm \mathrm{SE}$ (standard error) of the means. Different letters indicate significant differences according to Duncan's multiple-range test $(p=0.05)$.

\subsection{Principal Component Analysis (PCA)}

A principal component analysis (PCA) was conducted to highlight the effects of the treatments on all the parameters analyzed above. The first two principal components (PCs) explained $100 \%$ of the cumulative variance (Figure 6), with PC1 accounting for $76.71 \%$ and PC2 for $23.29 \%$. The PC1 was positively correlated with the nutraceutical compounds: $\mathrm{OH}$-tyrosol glucoside, verbascoside, oleuropein, ligstroside, luteolin, oleuropein aglycone, total polyphenols and with antioxidant activity assays (ABTS and DPPH), and negatively correlated with the stomatal conductance, fluorescence $\left(\mathrm{F}_{\mathrm{v}} / \mathrm{F}_{\mathrm{m}}\right)$, TSCA and dry matter of roots, leaves and total. Moreover, PC2 was positively correlated with shoots growth, leaf area, RWC and SPAD index.

PCA is effective in plotting the physiological, biometric, and nutraceutical parameters of the young olive trees in relation to the different treatments and their usefulness. In particular, the Kaolin $(\mathrm{K})$ treatment was positioned in the upper right quadrant of the PCA score plot, as it delivered the highest value of total polyphenols and all single polyphenols analyzed except for luteolin and verbascoside, and it showed the highest value of DPPH and SPAD. The pinolene $(\mathrm{V})$ treatment was positioned in the upper left quadrant of PCA score, as it delivered the highest value of RWC, $F_{v} / F_{m}$, shoots growth, TCSA and dry matter of roots, wood and total dry matter, whereas control was located in the lower left quadrant. 


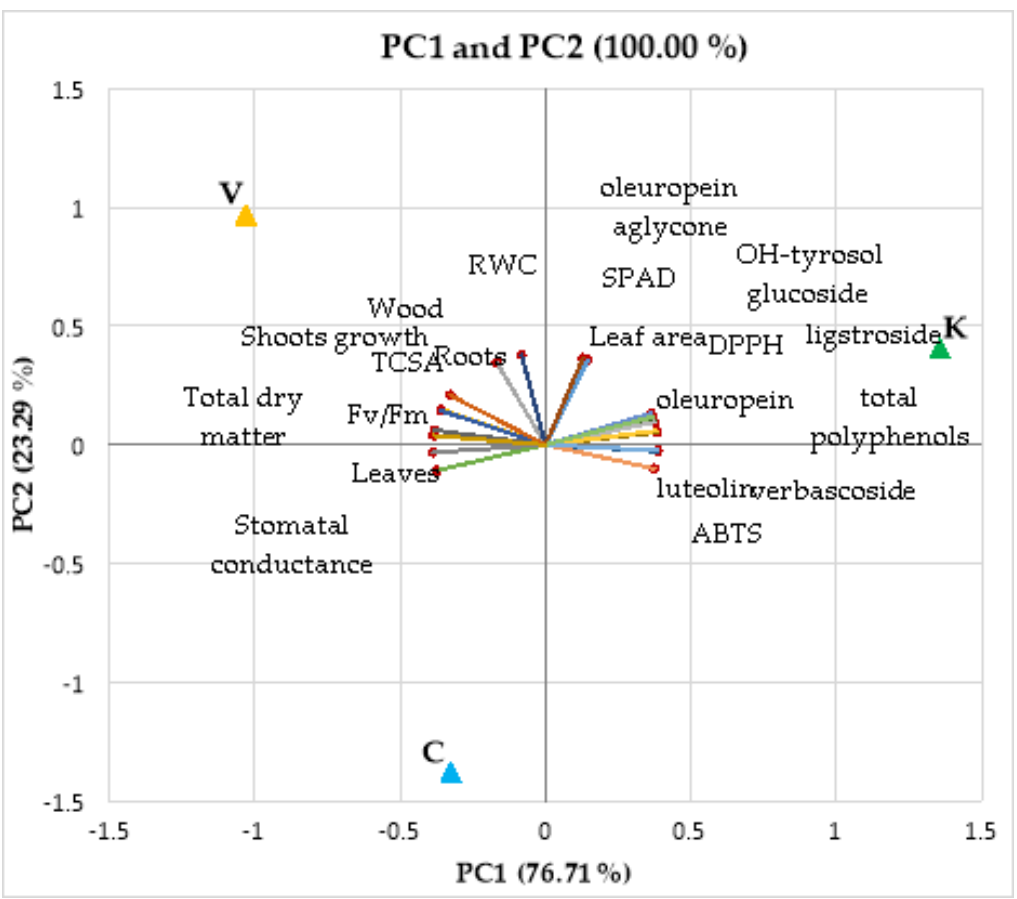

Figure 6. Principal component analysis (PCA) of biometric parameters (shoots growth, TCSA (trunk cross-sectional area), leaf area and dry matter of roots, wood, leaves and total dry matter), physiological parameters (stomatal conductance, RWC, SPAD and $F_{\mathrm{v}} / \mathrm{F}_{\mathrm{m}}$ ), nutraceutical parameters (OH-tyrosol glucoside, verbascoside, oleuropein, ligstroside, luteolin, oleuropein aglycone, total polyphenols, ABTS and DPPH), under the application of two anti-transpirants K: kaoline and V: di-1p-menthene in comparison to C: control. For the PCA, the parameters of stomatal conductance, RWC and SPAD analyzed were those of August, and for $F_{v} / F_{m}$ those of 2:00 p.m. (the values obtained after prolonged thermal stress were considered).

\section{Conclusions}

This preliminary study emphasizes the importance of using products based on kaolin and pinolene to improve the biometric, physiological and nutraceutical characteristics of young olive trees subjected to high thermal stress. As tentative results, foliar application of the anti-transpirant pinolene-based product improved the biometric parameters of the plants, in particular the shoots growth, TCSA, and total dry matter. Plants sprayed with the tested preparation were characterized by a higher relative water content (RWC) in leaves and a higher value of efficiency of photosystem II (PSII); this positive effect of 1-p-menthene on vegetative growth and development may be due to improved plant water status related to lower transpiration. Kaolin application also reduced stomatal conductance and similar to the $\mathrm{V}$ application, recorded higher values of leaf chlorophyll concentrations (SPAD) at the end of the vegetative season. In particular, interesting effects were recorded with the use of kaolin on the nutraceutical compounds of olive leaves; high contents of total polyphenols were recorded compared to control plants and this product showed a higher value of the antioxidant activity.

It is important to underline that further studies are necessary to determine the effect of these products on the biometric, physiological and nutraceutical parameters of mature olive trees cultivated in open field conditions in consecutive years and on the quality of the produce.

Author Contributions: Conceptualization, C.D.V., S.C., A.R. and Y.R.; methodology, S.C., C.D.V. and G.G.; software, A.C. and C.E.-N.; validation, C.D.V., Y.R., A.R. and G.G.; formal analysis, C.D.V.; investigation, A.C., S.C., C.E.-N., and G.G.; resources, C.D.V. and Y.R.; data curation, S.C., C.E.-N. and A.C.; writing-original draft preparation, S.C., A.C., G.G. and C.E.-N.; writing-review and editing, supervision, C.D.V., Y.R. and A.R.; project administration, Y.R. and C.D.V.; funding acquisition, Y.R. and C.D.V. All authors have read and agreed to the published version of the manuscript. 
Funding: This research received no external funding.

Acknowledgments: We would like to thank BIOGARD and MANICA for providing the antitranspirant products. We would also like to thank Giuseppe Melchionna for performing the ecophysiological measurements.

Conflicts of Interest: The authors declare no conflict of interest.

\section{References}

1. Moriondo, M. Modelling Olive Trees and Grapevines in a Changing Climate. Environ. Model. 2015, 72, 387-401. [CrossRef]

2. Orlandi, F.; Avolio, E.; Bonofiglio, T.; Federico, S.; Romano, B.; Fornaciari, M. Potential Shifts in Olive Flowering According to Climate Variations in Southern Italy. Meteorol. Appl. 2012, 20, 497-503. [CrossRef]

3. Fraga, H.; Pinto, J.G.; Viola, F.; Santos, J.A. Climate Change Projections for Olive Yields in the Mediterranean Basin. Int. J. Climatol. 2020, 40, 769-781. [CrossRef]

4. Mearns, L.O.; Rosenzweig, C.; Goldberg, R. Mean and variance change in climate scenarios: Methods, agricultural applications, and measures of uncertainty. Clim. Chang. 1997, 35, 367-396. [CrossRef]

5. Orlandi, F.; Ruga, L.; Romano, B.; Fornaciari, M. Olive flowering as an indicator of local climatic changes. Theor. Appl. Climatol. 2005, 81, 169-176. [CrossRef]

6. Urban, J.; Ingwers, M.; McGuire, M.A.; Teskey, R.O. Stomatal conductance increases with rising temperature. Plant Signal. Behav. 2017, 12, e1356534. [CrossRef] [PubMed]

7. Gregory, J.M.; Mitchell, J.F.B.; Brady, A.J. Summer Drought in Northern Midlatitudes in a Time-Dependent $\mathrm{CO}_{2} \mathrm{Climate}$ Experiment. J. Clim. 1997, 10, 25. [CrossRef]

8. Di Vaio, C.; Marallo, N.; Marino, G.; Caruso, T. Effect of Water Stress on Dry Matter Accumulation and Partitioning in Pot-Grown Olive Trees (Cv Leccino and Racioppella). Sci. Hortic. 2013, 164, 155-159. [CrossRef]

9. Angelopoulos, K.; Dichio, B.; Xiloyannis, C. Inhibition of photosynthesis in olive trees (Olea europaea L.) during water stress and rewatering. Exp. Bot. J. 1996, 47, 1093-1100. [CrossRef]

10. Fernández, J.E.; Moreno, F.; Girón, I.F.; Blázquez, O.M. Stomatal control of water use in olive tree leaves. Plant Soil 1997, 190, 179-192. [CrossRef]

11. Bacelar, E.A.; Santos, D.L.; Moutinho-Pereira, J.M.; Goncalves, B.C.; Ferreira, H.F.; Correia, C.M. Immediate Responses and Adaptative Strategies of Three Olive Cultivars under Contrasting Water Availability Regimes: Changes on Structure and Chemical Composition of Foliage and Oxidative Damage. Plant Sci. 2006, 170, 596-605. [CrossRef]

12. Bosabalidis, A.M.; Kofidis, G. Comparative Effects of Drought Stress on Leaf Anatomy of Two Olive Cultivars. Plant Sci. 2002, 163, 375-379. [CrossRef]

13. Boughalleb, F.; Hajlaoui, H. Physiological and Anatomical Changes Induced by Drought in Two Olive Cultivars (Cv Zalmati and Chemlali). Acta Physiol. Plant. 2011, 33, 53-65. [CrossRef]

14. Denaxa, N.-K. Comparative Effects of Exogenous Glycine Betaine, Kaolin Clay Particles and Ambiol on Photosynthesis, Leaf Sclerophylly Indexes and Heat Load of Olive Cv. Chondrolia Chalkidikis under Drought. Sci. Hortic. 2012, 137, 87-94. [CrossRef]

15. Wang, S. Genotypic Variation in Growth and Physiological Response to Drought Stress and Re-Watering Reveals the Critical Role of Recovery in Drought Adaptation in Maize Seedlings. Front. Plant Sci. 2016, 6, 15.

16. Perez-Martin, A.; Torres-Ruiz, J.M.; Fernández, J.E.; Diaz-Espejo, A.; Flexas, J.; Michelazzo, C.; Sebastiani, L. Physiological and genetic response of olive leaves to water stress and recovery: Implications of mesophyll conductance and genetic expression of aquaporins and carbonic anhydrase. In Proceedings of the XXVIII International Horticultural Congress on Science and Horticulture for People (IHC2010): International Symposium on CLIMWATER 2010: Horticultural Use of Water in a Changing Climate, Lisbon, Portugal, 22-27 August 2010; Fernández, J.E., Ferreira, M.I., Eds.; ISHS Acta Horticulturae: Leuven, Belgium, 2010; Volume 922, pp. 99-105.

17. Bacelar, E.A.; Santos, D.L.; Moutinho-Pereira, J.M. Physiological Behaviour, Oxidative Damage and Antioxidative Protection of Olive Trees Grown under Different Irrigation Regimes. Plant Soil. 2007, 292, 1. [CrossRef]

18. Petridis, A. Effect of Water Deficit on Leaf Phenolic Composition, Gas Exchange, Oxidative Damage and Antioxidant Activity of Four Greek Olive (Olea europaea L.) Cultivars. Plant Physiol. Biochem. 2012, 60, 1-11. [CrossRef]

19. Wungrampha, S.; Joshi, R.; Singla-Pareek, S.L.; Pareek, A. Photosynthesis and salinity: Are these mutually exclusive? Photosynthetica 2018, 56, 366-381. [CrossRef]

20. Munns, R.; Gilliham, M. Salinity Tolerance of Crops-What Is the Cost? New Phytol. 2015, 208, 668-673. [CrossRef]

21. Maxwell, K.; Johnson, G.N. Chlorophyll fluorescence-A practical guide. J. Exp. Bot. 2000, 51, 659-668. [CrossRef]

22. Roháček, K.; Soukupová, J.; Barták, M. Chlorophyll fluorescence: A wonderful tool to study plant physiology and plant stress. Plant Cell Compart.-Sel. Top. Res. Signpost Kerala India 2008, 37, 41-104.

23. Del Amor, F.M. Growth, Photosynthesis and Chlorophyll Fluorescence of Sweet Pepper Plants as Affected by the Cultivation Method. Ann. Appl. Biol. 2006, 148, 133-139. [CrossRef]

24. Cantore, V.; Pace, B.; Albrizio, R. Kaolin-Based Particle Film Technology Affects Tomato Physiology, Yield and Quality. Environ. Exp. Bot. 2009, 66, 279-288. [CrossRef]

25. Lombardini, L.; Harris, M.K.; Glenn, D.M. Effects of particle film application on leaf gas exchange, water relations, nut yield, and insect populations in mature pecan trees. HortScience 2005, 40, 1376-1380. [CrossRef] 
26. Rosati, A.; Metcalf, S.G.; Buchner, R.P.; Fulton, A.E.; Lampinen, B.D. Effects of kaolin application on light absorption and distribution, radiation use efficiency and photosynthesis of almond and walnut canopies. Ann. Bot. 2007, 99, 255-263. [CrossRef]

27. Palliotti, A.; Poni, S.; Berrios, J.G.; Bernizzoni, F. Vine performance and grape composition as affected by early-season source limitation induced with anti-transpirants in two red Vitis vinifera L. cultivars. Aust. J. Grape Wine Res. 2010, 16, 426-433. [CrossRef]

28. Gu, S.; Fuchigami, L.H.; Cheng, L.; Guak, S.H.; Shin, C. Effects of antitranspirant and leaching on medium solution osmotic potential, leaf stomatal status, transpiration, abscisic acid content and plant growth in'Early Girl'tomato plants (Lycopersicon esculentum). J. Hortic. Sci. 1998, 73, 473-477. [CrossRef]

29. Mola, I.D.; Conti, S.; Cozzolino, E.; Melchionna, G.; Ottaiano, L.; Testa, A.; Sabatino, A.; Rouphae, Y.; Mori, M. Plant-Based Protein Hydrolysate Improves Salinity Tolerance in Hemp: Agronomical and Physiological Aspects. Agronomy 2021, 11, 342. [CrossRef]

30. Di Vaio, C.; Graziani, G.; Gaspari, A.; De Luca, L.; Aiello, A.; Cirillo, A.; Bruno, A.; Romano, R.; Ritieni, A. Drupe Characters, Fatty Acids, Polyphenolic and Aromatic Profile of Olive Oil Obtained from "Oliva Bianca", Minor Autochthonous Cultivar of Campania. Plants 2021, 10, 1119. [CrossRef] [PubMed]

31. Talhaoui, N.; Gómez-Caravaca, A.M.; León, L.; De la Rosa, R.; Segura-Carretero, A.; Fernández-Gutiérrez, A. Determination of Phenolic Compounds of 'Sikitita' Olive Leaves by HPLC-DAD-TOF-MS. Comparison with Its Parents 'Arbequina' and 'Picual' Olive Leaves. LWT 2014, 58, 28-34. [CrossRef]

32. Dini, I.; Graziani, G.; Fedele, F.L.; Sicari, A.; Vinale, F.; Castaldo, L.; Ritieni, A. Effects of Trichoderma Biostimulation on the Phenolic Profile of Extra-Virgin Olive Oil and Olive Oil By-Products. Antioxidants 2020, 9, 284. [CrossRef] [PubMed]

33. Re, R.; Pellegrini, N.; Proteggente, A.; Pannala, A.; Yang, M.; Rice-Evans, C. Antioxidant Activity Applying an Improved ABTS Radical Cation Decolorization Assay. Free Radic. Biol. Med. 1999, 26, 1231-1237. [CrossRef]

34. Brand-Williams, W.; Cuvelier, M.E.; Berset, C. Use of a Free Radical Method to Evaluate Antioxidant Activity. LWT 1995, 28, 25-30. [CrossRef]

35. Roussos, P.A.; Denaxa, N.-K.; Damvakaris, T.; Stournaras, V.; Argyrokastritis, I. Effect of Alleviating Products with Different Mode of Action on Physiology and Yield of Olive under Drought. Sci. Hortic. 2010, 125, 700-711. [CrossRef]

36. MI, A.D.; Abd El-Rhman, I.E.; Sahar, A.F. Effect of Some Antitranspirants and Supplementery Irrigation on Growth, Yield and Fruit Quality of Sultani Fig (Ficus carica) Grown in the Egyption Western Coastal Zone under Rainfed Conditions. AGBR 2009, 5, 899-908.

37. Davenport, D.C.; Fisher, M.A.; Hagan, R.M. Some counteractive effects of antitranspirants. Plant Physiol. 1972, $49,722-724$. [CrossRef]

38. Di Vaio, C.; Marallo, N.; Di Lorenzo, R.; Pisciotta, A. Anti-transpirant effects on vine physiology, berry and wine composition of cv. Aglianico (Vitis vinifera L.) grown in south Italy. Agronomy 2019, 9, 244. [CrossRef]

39. Di Vaio, C.; Villano, C.; Lisanti, M.T.; Marallo, N.; Cirillo, A.; Di Lorenzo, R.; Pisciotta, A. Application of Anti-Transpirant to Control Sugar Accumulation in Grape Berries and Alcohol Degree in Wines Obtained from Thinned and Unthinned Vines of cv. Falanghina (Vitis vinifera L.). Agronomy 2020, 10, 345. [CrossRef]

40. Nielson, R.E.; Jarvis, P.G. Photosynthesis in Sitka Spruce (Picea sitchensis (Bong.) Carr.): VI. Response of Stomata to Temperature. J. Appl. Ecol. 1975, 12, 879-891. [CrossRef]

41. Turner, N.C. Concurrent comparisons of stomatal behavior, water status, and evaporation of maize in soil at high or low water potential. Plant Physiol. 1975, 55, 932-936. [CrossRef] [PubMed]

42. Song, X.; Wang, W.; Zhang, C.; Ma, Q.; Li, Y. Postharvest physiochemical responses of cut rose (Rosa hybrida L.) to antitranspirant and vacuum cooling. Philipp. Agric. Sci. 2011, 94, 368-374.

43. Misra, A.K.; Das, B.K.; Datta, J.K.; De, G.C. Effect of antitranspirants on water status and growth pattern of Mulberry (Morus alba L.) under two levels of irrigation. Indian J. Agric. Res. 2009, 43, 307-310.

44. Glenn, D.M. The mechanisms of plant stress mitigation by kaolin-based particle films and applications in horticultural and agricultural crops. HortScience 2012, 47, 710-711. [CrossRef]

45. Del Amor, F.M.; Cuadra-Crespo, P.; Walker, D.J.; Cámara, J.M.; Madrid, R. Effect of foliar application of antitranspirant on photosynthesis and water relations of pepper plants under different levels of $\mathrm{CO}_{2}$ and water stress. J. Plant Physiol. 2010, 167, 1232-1238. [CrossRef] [PubMed]

46. Mikiciuk, G.; Mikiciuk, M.; Ptak, P. The effects of anitranspirant di-1-p-menthene on some physiological traits of strawberry. J. Ecol. Eng. 2015, 16, 161-167. [CrossRef]

47. Abdel-Fattah, G.H. Response of water-stressed rose of China (Hibiscus rosa-sinensis L.) plant to treatment with calcium carbonate and vapor gard antitranspirants. J. Appl. Sci. Res. 2013, 9, 3566-3572.

48. Björkman, O.; Demmig, B. Photon yield of $\mathrm{O}_{2}$ evolution and chlorophyll fluorescence characteristics at $77 \mathrm{~K}$ among vascular plants of diverse origins. Planta 1987, 170, 489-504. [CrossRef]

49. Segura-Monroy, S.; Uribe-Vallejo, A.; Ramirez-Godoy, A.; Restrepo-Diaz, H. Effect of kaolin application on growth, water use efficiency, and leaf epidermis characteristics of Physallis peruviana seedlings under two irrigation regimes. J. Agric. Sci. Technol. 2015, 17, 1585-1596.

50. Latocha, P.; Ska, M.C.; Pietkiewicz, S.; Kalaji, M.H. Preliminary Assessment of Antitranspirant Vapor Gard ${ }^{\circledR}$ Influence on Actinidia Arguta Growing under Drought Stress Conditions. Ann. Wars. Univ. Life Sci. 2009, 30, 149-150.

51. Lawlor, D.W. Limitation to Photosynthesis in Water-Stressed Leaves: Stomata vs. Metabolism and the Role of ATP. Ann. Bot. 2002, 89, 871-885. [CrossRef] 
52. Percival, G.C.; Keary, I.P.; Marshall, K. The use of film-forming polymers to control Guignardia leaf blotch and powdery mildew on Aesculus hippocastanum L. and Quercus robur L. Arboric. Urban For. 2006, 32, 100.

53. Anderson, J.M. Photoregulation of the composition, function, and structure of thylakoid membranes. Annu. Rev. Plant Physiol. 1986, 37, 93-136. [CrossRef]

54. Shekour, G.M.; Brathwaite, R.A.I.; McDavid, C.R. Dry Season Sweet Corn Response to Mulching and Antitranspirants1. J. Agron. 1987, 79, 629-631. [CrossRef]

55. Denaxa, N.-K.; Damvakaris, T.; Roussos, P.A. Antioxidant Defense System in Young Olive Plants against Drought Stress and Mitigation of Adverse Effects through External Application of Alleviating Products. Sci. Hortic. 2020, 259, 108812. [CrossRef]

56. Brillante, L.; Belfiore, N.; Gaiotti, F.; Lovat, L.; Sansone, L.; Poni, S.; Tomasi, D. Comparing Kaolin and Pinolene to Improve Sustainable Grapevine Production during Drought. PLoS ONE 2016, 11, e0156631. [CrossRef] [PubMed]

57. Valentini, G.; Pastore, C.; Allegro, G.; Muzzi, E.; Seghetti, L.; Filippetti, I. Application of Kaolin and Italian Natural Chabasite-Rich Zeolitite to Mitigate the Effect of Global Warming in Vitis vinifera L. cv. Sangiovese. Agronomy 2021, 11, 1035. [CrossRef] 